\title{
GIS-BASED THERMAL LOAD ESTIMATION OF BUILDINGS IN THE NATIONAL SCIENCE COMPLEX, UP DILIMAN
}

\author{
C. A. Tatlonghari ${ }^{1 *}$, J. A. Principe ${ }^{2}$ \\ ${ }^{1}$ National Graduate School of Engineering, University of the Philippines Diliman, Quezon City - catatlonghari@up.edu.ph \\ ${ }^{2}$ Dept. of Geodetic Engineering, University of the Philippines Diliman, Quezon City - japrincipe@up.edu.ph
}

KEY WORDS: Thermal load, 3D visualization, DTM, smart city, sustainability

\begin{abstract}
:
Building thermal load is the energy exhausted to maintain a specific indoor temperature in comparison to the outdoor temperature. Majority of this energy makes use of a considerable amount of fossil fuels which contributes to greenhouse gases emission leading to global warming. Thermal load estimation of buildings allows people to identify infrastructures in need for retrofit for a more sustainable and smart urban management. This paper presents a small-scale study to estimate the thermal cooling load of fourteen (14) buildings in the National Science Complex of the University of the Philippines Diliman. Results of the annual cooling load calculation for the year 2020 was reported with an estimated lowest cooling load of 1,618 kW for the Philippine Atmospheric, Geophysical and Astronomical Services Administration (PAGASA) observatory and the highest cooling load of 13,484 $\mathrm{kW}$ for the Institute of Mathematics. The values calculated was an overestimation as the entire building was set up as a homogenous cold room without any windows or doors. For future work, it is recommended that input data be supplemented with digital surface model (DSM) and triangulated irregular network (TIN) raster data derived from Light Detection and Ranging (LiDAR) to not only categorize but assign specific values over each building group of the study area.
\end{abstract}

\section{INTRODUCTION}

Development in urbanized areas is expected to increase as the global population continues to surge exponentially (UN, 2014). As such, there is a need for sustainable urban development as production of energy from different sources may not be able to keep in step with the current rate of population growth.

Load monitoring models can be used to calibrate building thermal loads for smart meter management that can lead to high power savings (Enríquez, 2017). Such models can assist in identifying which buildings or infrastructures in urban areas need to be retrofitted for a more sustainable use of energy that benefits energy system management operations and energy optimization in smart cities.

Bizjak, et. al (2021) utilized LiDAR data and estimated the thermal load calculation of an urban area over $6.153 \mathrm{~km}^{2}$ in size. LiDAR point data was processed to generate three-dimensional (3D) models and TIN data. Using triangle meshes generated from the TIN data, the incoming solar irradiance and net long-wave radiation exchange were calculated which were then used to estimate the cumulative thermal load. Upon considering the window/door solar penetration of each building, the annual thermal cooling and heating load of buildings within Maribor City, Slovenia was estimated.

The objective of this study is to estimate the cooling load of the buildings within the National Science Complex (NSC) in UP Diliman with the use of digital elevation models and GIS techniques. NSC comprises various administrative and academic buildings with indoor equipment. Being a tropical country, temperatures during the dry months in the Philippines are extremely hot affecting the cooling load requirement for each building.

The specific objectives of this study are to: (1) generate a 3D visualization of the thermal loading of buildings in the NSC; (2) estimate the thermal cooling load of buildings; and (3) visualize results in a $3 \mathrm{D}$ environment to clearly show the entirety of the study area.

\subsection{Scope and Limitations}

The study area was the National Science Complex (NSC) in the University of the Philippines, Diliman (Fig. 1). NSC (14 $38^{\prime}$ $\left.58.78^{\prime \prime} \mathrm{N}, 121^{\circ} 4^{\prime} 15.74^{\prime \prime} \mathrm{E}\right)$ has an approximate area of 21.9 hectares. The focus of this study will be the fourteen (14) main buildings within the complex.

The study will only be limited with the use of publicly available remotely sensed data such as RADARSAT Digital Elevation Model (DEM), daytime climate data within or near the study area, and general variables for the cooling load computation parameters based on other studies. No ground validation was made due to mobility restrictions brought by the ongoing pandemic.

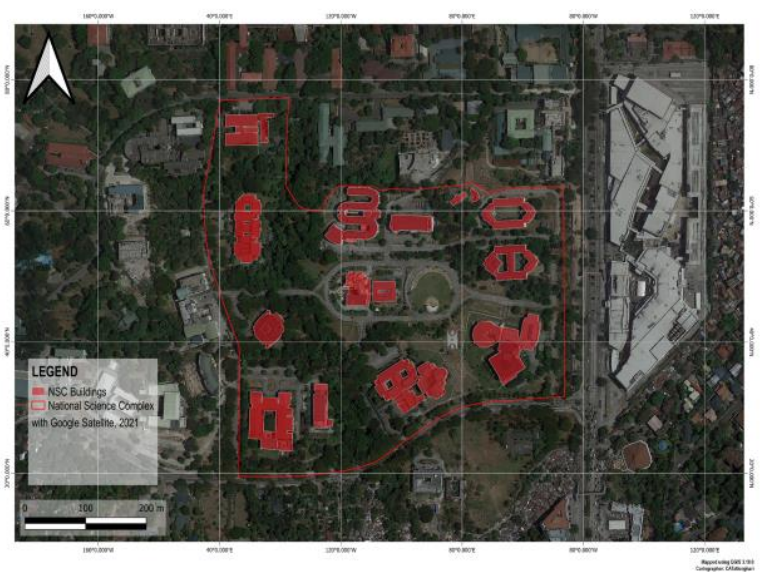

Figure 1. The National Science Complex (NSC) in UP Diliman, Quezon City. 


\subsection{Review of Related Literature}

1.2.1 Thermal Load Estimation: Building thermal load is defined as the energy exhausted to maintain a specific indoor temperature in comparison to the outdoor temperature. Thermal load estimation is usually calculated for peak, normal, and floating loads (Lebrun, 2021) which includes cases such as cooling load for the summer season and heating load for the winter season.

Thermal loading estimation can quantize cooling and heating over a building. A majority of total global energy use and requires commensurate amounts of resources which contribute significantly to global warming (Booten et. al, 2021). Traditionally, thermal loading estimation amounted to the use of specific equipment and then later on reducing the heat transfer and air infiltration to the specific building (Booten et. al, 2021).

1.2.2 3D Visualization: $2.5 \mathrm{D}$ visualization has been widely available for most spatial data visualization with the use of various GIS software and digital elevation model data are used for such cases. Currently, 3D GIS can generate 3D visualization which improves the usability and flexibility of said data $(\mathrm{Wu}$ Xincai, 2002).

\section{METHODOLOGY}

\subsection{Data}

A number of spatial and non-spatial data was used in this study including Radarsat Digital Terrain Model (DTM), 2020 monthly average of daytime temperature over the entire study area, digitized building footprints, and parameters for calculating the cooling load (e.g. incoming solar irradiance, solar radiation absorptance, etc). Moreover, software applications were used to process the spatial data and the 3D environment visualization. QGIS v3.10.0 was used to generate GIS data including digitization of building features in the study area. Virtual Terrain Project (VTP) is an application which consists of VTBuilder and Enviro. VTP was used to create interactive 3D environments. A timelapse was generated from VTP with the GIMP v2.10.24 for compiling images into an animation.

Limited data was acquired for this study as only the Radarsat DTM data was acquired from National Mapping and Resource Information Authority (NAMRIA). The monthly climate data was taken from open-sourced and publicly available data. The daytime temperature was only considered and later the average was taken. The building metadata for NSC were just overall generalizations of the building code in the Philippines. Table 1 shows the different data and values used in this study, especially the values set in estimating the building cooling load inside NSC.

\subsection{Methods}

The general methodology of this study has four major parts as shown in Fig. 2.

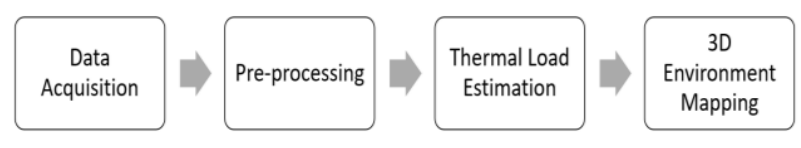

Figure 2. General Methodology

\begin{tabular}{|l|l|}
\hline Data & Source \\
\hline Radarsat DTM & NAMRIA \\
\hline Building Material & $\begin{array}{l}\text { Office of the Campus Architect } \\
(2021)\end{array}$ \\
\hline Outdoor Air Temperature & Accuweather, 2020 \\
\hline Incoming Solar Irradiance & Solar Electricity Handbook, 2021 \\
\hline Solar Radiation Absorptance & Engineering ToolBox, 2021 \\
\hline $\begin{array}{l}\text { Convective Heat Transfer } \\
\text { Coefficient }\end{array}$ & Chávez-Galán et. al., 2014 \\
\hline $\begin{array}{l}\text { Overall Heat Transfer } \\
\text { Coefficient }\end{array}$ & Colorado Energy, 2019 \\
\hline Indoor Air Temperature & Katili et. al., 2015 \\
\hline
\end{tabular}

Table 1. List of acquired data.

2.2.1 Digitization of Building Footprints: Buildings within the NSC were digitized using the online Google Satellite and ESRI Satellite layers from QGIS v3.10.0 as references. Upon digitizing, the available satellite perspective and shadows casted by the buildings were considered.

Additional attributes were added such as the roof or floor area and wall area which was calculated by using the perimeter and a third of the product of the perimeter and building height, respectively. The building height was set to 12 meters by following the building code which set each storey height to 4 meters as the average story-level for the fourteen buildings in NSC was 3-stories.

2.2.2 Cooling Load Estimation: In order to estimate the cooling load, the solar air temperature must first be calculated using Eq (1)

$$
T_{\text {sol-air }}(t)=T_{\text {outdoor }}(t)+\frac{\alpha I(t)+L(t)}{h}\left({ }^{\circ} \mathrm{C}\right)
$$

where

$$
\begin{aligned}
& T_{\text {outdoor }}=\text { outdoor air temperature } \\
& \alpha=\text { solar radiation absorptance } \\
& I=\text { total incoming solar irradiance } \\
& h=\text { convective heat transfer coefficient } \\
& L=\text { net long-wave radiation exchange }=\frac{h}{\Delta t}
\end{aligned}
$$

Outdoor temperature values were set to the average 2020 daytime temperature from the acquired data while the radiation absorptance value was set based on the assumption that concrete material is the most likely building material for most of the NSC buildings. Such an assumption was based on the information stated via online correspondence with the Office of the Campus Architect in UP Diliman. The value for the total solar radiation incident is dependent on the area and the orientation of the surface in contact with solar energy. In this case, the incoming solar irradiance value was taken from the online Solar Irradiance Calculator and the location was set to Manila, which was closest available data for NSC, while its surface orientation was set to a flat surface. Lastly, the convective heat transfer coefficient depends on the building material (concrete) and the material (air) surrounding it. The wind speed in the vicinity of the study area is 
6.4 to $8.0 \mathrm{~m} / \mathrm{s}$ according to Elliot (2000). Considering the building material and the wind speed, the convective heat transfer coefficient was set to $62.83 \mathrm{~W} / \mathrm{m}^{2} \mathrm{~K}$ (Chávez-Galán et. al, 2014).

The cooling load was computed using Eq (2) below.

$$
Q(t)=U A\left(T_{\text {sol-air }}(t)-T_{\text {indoor }}(t)(W)\right.
$$

where

$$
\begin{aligned}
& U=\text { overall heat transfer coefficient } \\
& A=\text { area of solar affected building surface } \\
& T_{\text {sol-air }}=\text { solar air temperature } \\
& T_{\text {indoor }}=\text { expected indoor air temperature }
\end{aligned}
$$

The overall heat transfer coefficient was set to the concrete masonry unit with a thickness of 8 inches being the most common material used in the country according to Presidential Decree No. 1096, the National Building Code of the Philippines. The area is set to the sum of the roof area and one-fourth of the wall area as the solar energy interaction with buildings is usually limited to this amount. As for the indoor air temperature, when the indoor air temperature was at $25^{\circ} \mathrm{C}$ it is considered comfortable (Katili et. al, 2015).

Thermal cooling load was calculated for each of the fourteen buildings in NSC and inputted to the attribute table of the digitized buildings.

2.2.3 3D Visualization: To visualize the thermal cooling load in 3D, the DTM from Radarsat was loaded onto the VTBuilder software which generated a terrain file to be inputted into Enviro. The same process was done with the road and building shapefiles. Both VTBuilder and Enviro were included in the Virtual Terrain Project (VTP).

The 3D scene was then modified accordingly for a more realistic view by adding vegetation. An abstract feature was also included to symbolize the buildings by range of their cooling load. Labels were also added showing the building's cooling load in $\mathrm{kW}$.

Lastly, a timelapse path of the 3D animation was generated presenting the general area within the NSC. Sixty-six still images were generated in the process which were then compiled to produce an animation.

\section{RESULTS AND DISCUSSION}

\subsection{Cooling Load Estimation}

3.1.1 Solar Air Temperature Calculation: The calculated solar air temperature values are shown in Table 2 . It can be noted that the values for all buildings are the same as the building materials were all set to concrete and the wall thickness to 8 inches as stated in section 2.4.

The outdoor temperature was the combined average of the monthly daytime temperature which is shown to be $32.168^{\circ} \mathrm{C}$. As the incoming solar irradiance data for a flat-surfaced material were acquired per month, the average was also computed to get the year 2020 data $-450.25 \mathrm{~kW} / \mathrm{m}^{2}$. The value for the solar radiation absorptance for concrete is 0.6 . The convective heat transfer coefficient is calculated by considering the building material which is concrete and the wind velocity of $8.0 \mathrm{~m} / \mathrm{s}$ for the outside environment. The value $62.83 \mathrm{~W} / \mathrm{m}^{2} \mathrm{~K}$ was calculated and used to compute the net long-wave radiation exchange. Finally, the solar air temperature was computed using Eq. (1).
3.1.2 Thermal Cooling Load Estimation: The cooling load for the buildings in NSC was estimated in Watts. It can be seen in Table 3 that the area is the only variable whose value differs for each building. As such, the cooling load computed seems overestimated due to the generalized data. A similar study by Zhao (2018) estimated the cooling load at around $790-860 \mathrm{~kW}$ for a specific building with almost the same area as that of the Institute of Mathematics (IM). However, for this study, the calculated cooling load of the IM building was $13,484 \mathrm{~kW}$.

In calculating the cooling load of the buildings in NSC, the area used for this calculation is the combined wall and roof area of each building. As for the overall heat transfer coefficient, the value for an 8-inch concrete was considered from the Archtoolbox website and then converted to metric units resulting in $6.303 \mathrm{~W} / \mathrm{m}^{2} \mathrm{~K}$. The average indoor air temperature is set to $25^{\circ} \mathrm{C}$ and the solar air temperature was calculated previously. Using Eq. 2, the cooling load of each building was computed as shown in Table 3.

As the area of each building was the main varying parameter in this study, the building with the largest area has the highest cooling load and vice versa. IM has a cooling load of $13,484 \mathrm{~kW}$, while the PAGASA Astronomical Observatory has 1,618 kW. Lastly, the average cooling load of the fourteen (14) buildings in NSC is $7,137 \mathrm{~kW}$.

\subsection{D Environment Visualization}

3.2.1 VTP 3D Environment: The generated 3D environment is shown in Fig. 5. Buildings were color-coded according to the range of cooling load: green for 0 to $5,000 \mathrm{~kW}$, yellow for 5,000 to $10,000 \mathrm{~kW}$, and red for $>10,000 \mathrm{~kW}$. Additionally, the cooling load values in $\mathrm{kW}$ are indicated on top of each building feature.

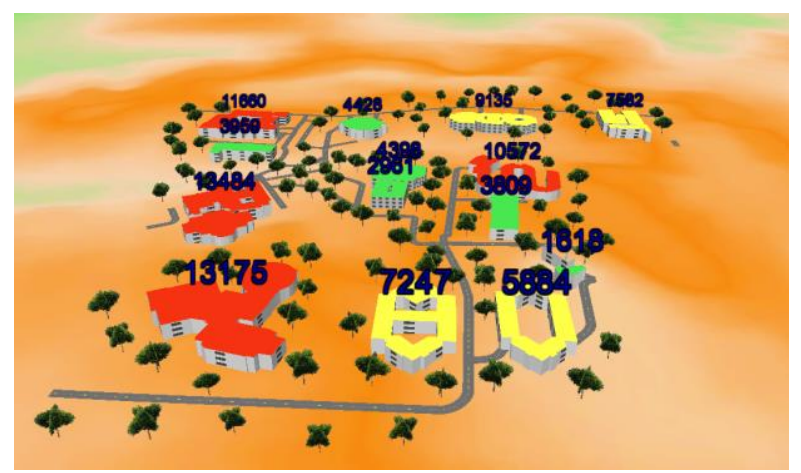

Figure 5. 3D Model using SRTM DTM.

The 3D environment is able to show the study area in its entirety. Using the provided DTM, the terrain is considered when visualizing the roads, vegetation, and buildings. Additionally, the building height can be set according to the data acquired.

This visualization can be useful when presenting the solar penetration within NSC, since the elevation and building height are considered. Furthermore, the vegetation can even be set as realistically as possible to have near-realistic simulation.

4.2.2. VTP 3D Animation: Frames as seen in the animation generated by VTP are shown in Fig. 6. The terrain, roads and buildings were displayed using available spatial data. Vegetation and environment were modified in Enviro to visualize the environment in a more realistic manner. As the thermal load was represented by the color of the roof, the 3D animation shows the spatial distribution of buildings within the NSC. 


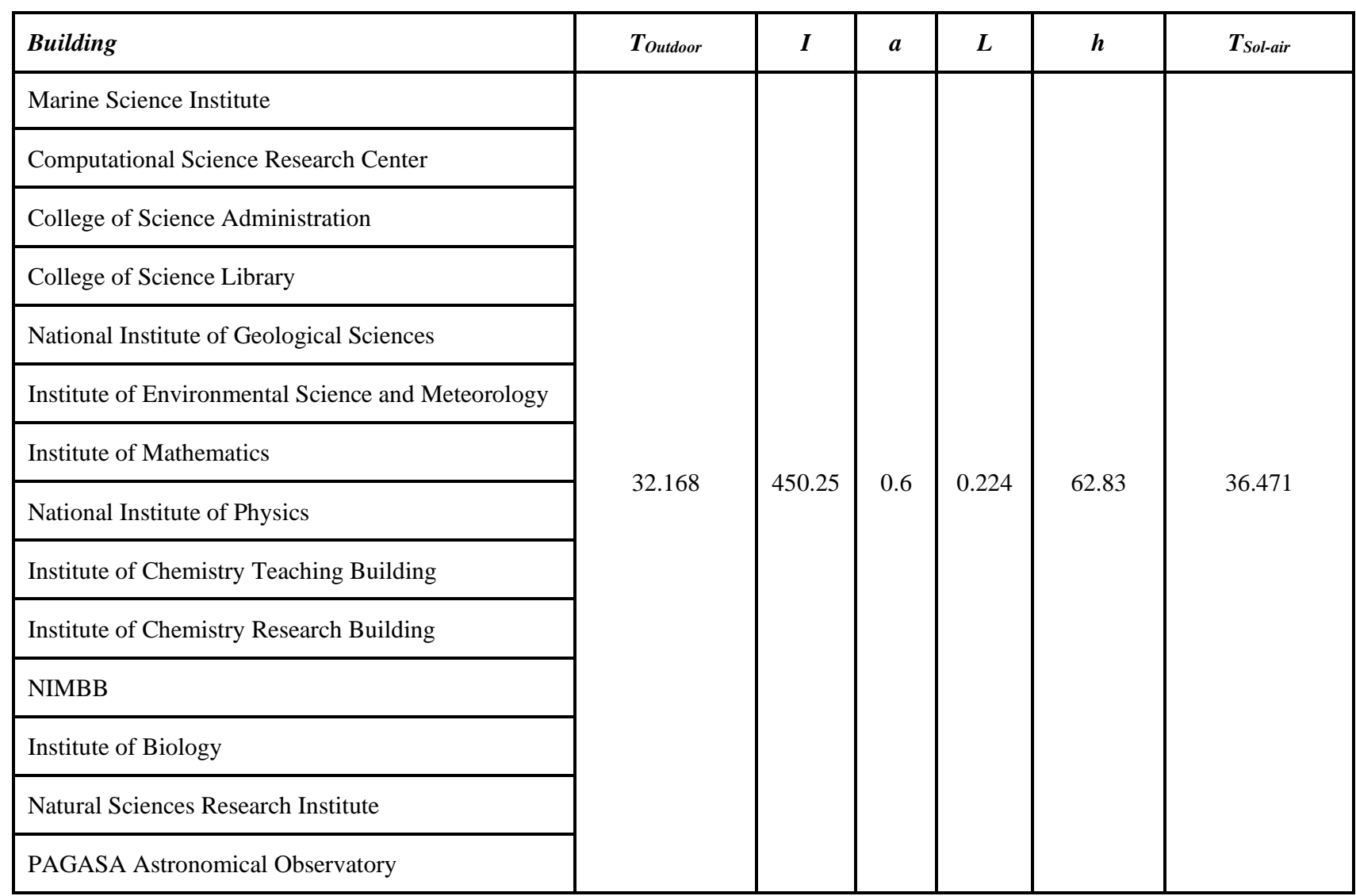

Table 2. Solar air temperature calculation (see section 2.2.2 for information on the variables).

\begin{tabular}{|c|c|c|c|c|c|}
\hline Building & $T_{\text {Sol-air }}$ & Area & $\boldsymbol{U}$ & $T_{\text {indoor }}$ & Cool Load (KW) \\
\hline Marine Science Institute & \multirow{14}{*}{36.471} & 5091.98 & \multirow{14}{*}{6.303} & \multirow{14}{*}{25.000} & $9,134.66$ \\
\hline Computational Science Research Center & & 1650.52 & & & $2,960.93$ \\
\hline College of Science Administration & & 2451.71 & & & $4,398.20$ \\
\hline College of Science Library & & 2468.26 & & & $4,427.89$ \\
\hline National Institute of Geological Sciences & & 6499.53 & & & $11,659.72$ \\
\hline Institute of Environmental Science and Meteorology & & 2207.06 & & & $3,959.31$ \\
\hline Institute of Mathematics & & 7516.61 & & & $13,484.30$ \\
\hline National Institute of Physics & & 7344.44 & & & $13,175.44$ \\
\hline Institute of Chemistry Teaching Building & & 4039.66 & & & $7,246.88$ \\
\hline Institute of Chemistry Research Building & & 3280.03 & & & $5,884.15$ \\
\hline NIMBB & & 2123.14 & & & $3,808.76$ \\
\hline Institute of Biology & & 5892.97 & & & $10,571.60$ \\
\hline Natural Sciences Research Institute & & 4226.49 & & & $7,582.04$ \\
\hline PAGASA Astronomical Observatory & & 901.80 & & & $1,617.77$ \\
\hline
\end{tabular}

Table 3. Cooling Load Calculation (see section 2.2.2 for information on the variables). 
With the addition of a more accurate and up-to-date building metadata, this $3 \mathrm{D}$ animation would be able to show the buildings with correct building height and window-door simulation. Such updated building information will significantly improve both the estimated thermal cooling load and 3D visualization. Specific locations with increased penetration of solar radiation could be located and will be able to aptly show these details easily as compared to $2 \mathrm{D}$ visualization with an updated metadata of buildings.

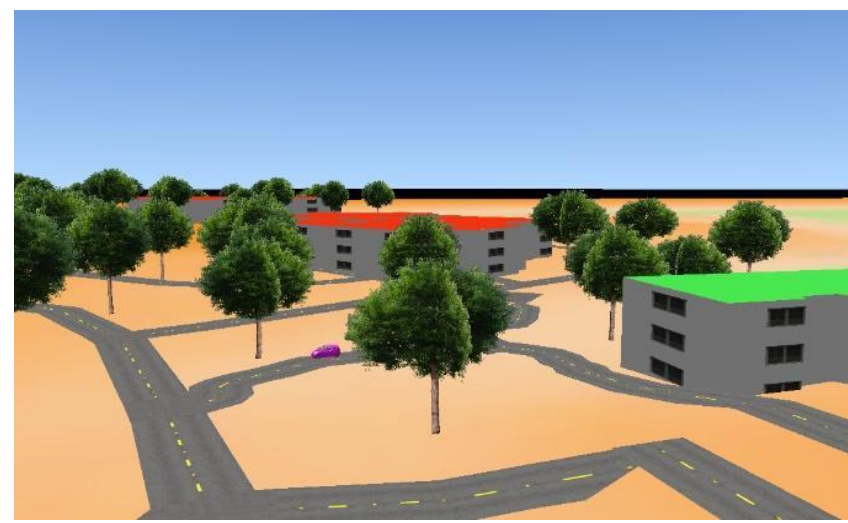

(a)

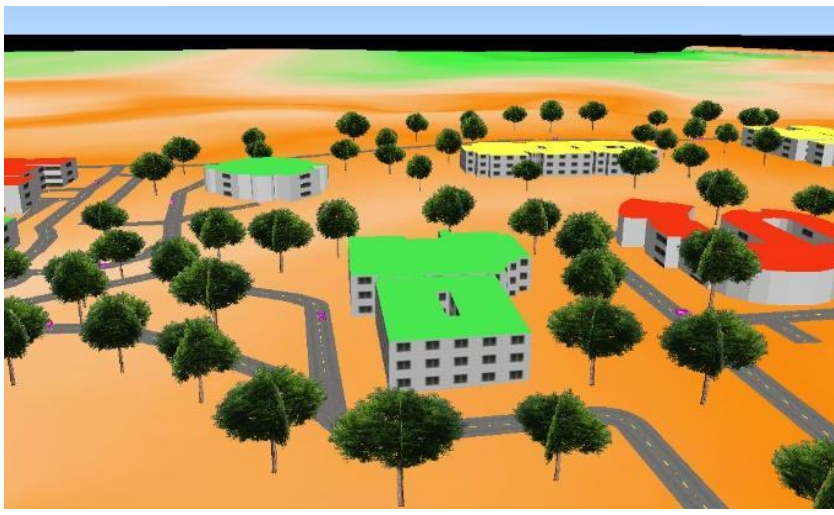

(b)

Figure 6. Snippets of the 3D Animation: (a) towards the Institute of Mathematics building; and (b) overview of buildings in western side of the NSC.

The 3D animation allows for a more interactive and immersive experience with the $3 \mathrm{D}$ environment. The movement is able to show the study area from different perspectives such as in the middle of the study area or by the bird's view near specific buildings.

\section{CONCLUSION AND RECOMMENDATIONS}

This study has presented a methodology to estimate the cooling load of each building in the National Science Complex. The PAGASA Observatory has the lowest estimated cooling load $(1,618 \mathrm{~kW})$ while the highest load $(13,484 \mathrm{~kW})$ was estimated for the Institute of Mathematics building. It should be noted that the estimated cooling load was mainly derived from generalized values of parameters considered in this study due to limited data available. Considering only the total floor area, it is therefore expected that the smallest building had the lowest cooling load and vice versa.
The 3D visualization of the estimated cooling load showed the effect of the size of each building in relation to the estimated cooling load. However, with the lack of the data, such as building metadata (i.e., material, window and door location, open areas and air-conditioned areas, etc.) and high-resolution LiDARDEM, parameters were generalized to uniform values for the cooling load estimation.

For future work, more accurate and complete data must be used including climate data with accurate spatial coordinates (i.e., not using Manila data for Quezon City study area). The metadata for each building must also be complete so as not to generalize the entirety of the features as one homogenous object and should also include accurate building height and shape. Lastly, windows and door penetrations should be well considered to represent variations for the cooling load estimation per building.

As this study merely considered the entire building as one big, air-conditioned room, it is also helpful to note which areas make use of air-conditioning units from those which don't. This additional information will help in estimating the cooling load for each building more accurately and realistically.

Lastly, it is recommended to use LiDAR data to generate a DEM with higher spatial resolution than SAR-based DEMs. With LiDAR data, a digital surface model (DSM) can be generated which considers man-made features other than buildings. Accurate delineation of roof details (e.g., shape, aspect, slope) is also possible with LiDAR point cloud data and an updated incoming solar irradiance data. LiDAR point cloud data can be transformed into a raster by generating TIN whose mesh triangles can be assigned certain values which are in line with the incoming solar irradiance and net long-wave radiation exchange used in calculating the thermal load.

\section{ACKNOWLEDGEMENTS}

The authors would like to thank the National Mapping and Resource Information Authority for providing the RADARSAT DEM data, and the Offices of the Vice-Chancellor for Planning and Development and Campus Architect of UP Diliman for data on the NSC buildings.

\section{REFERENCES}

AccuWeather, Inc., 2020: Quezon City, Metropolitan Manila, Monthly Weather. [Weather Report]. Retrieved from https://www.accuweather.com/en/ph/quezoncity/264873/january-weather/264873 ?year=2020.

Achenbach, M., Lahmer, T.. Morgenthal, G., 2017: Identification of the thermal properties of concrete for the temperature calculation of concrete slabs and columns subjected to a standard fire- Methodology and proposal for simplified formulations. $\begin{array}{llll}\text { Fire } & \text { Safety } & \text { Journal. } & \text { 80-86. }\end{array}$ doi.org/10.1016/j.firesaf.2016.12.003.

Bizjak, M., Zalik B., Stumberger G., Lukac, N., 2020: Largescale estimation of buildings' thermal load using LiDAR data. Energy and Buildings. 231. doi.org/10.1016/j.enbuild.2020.110626.

Booten, C., Rao, P., Rapp, V., Jackson, R., Prasher, R., 2021: Theoretical Minimum Thermal Load in Buildings. Joule. 5. 2446. doi.org/10.1016/j.joule.2020.12.015. 
Chávez-Galán, J., Almanza, R., Rodríguez-Cuevas, N., 2014: Convective heat transfer coefficients: experimental estimation and its impact on thermal building design for walls made of different mexican building materials. Concreto y cemento. Investigación y desarrollo. 5. 26-38.

Dornelles, K., Roriz, V., 2007: Solar Absorptance of Building Opaque Surfaces. CISBAT 2007 International Conference. doi.org/10.13140/RG.2.1.4465.3285.

Elliott, D., 2000: Philippines Wind Energy Resource Atlas Development. Business and Investment Forum for Renewable Energy and Energy Efficiency in Asia and the Pacific Region.

Engineering ToolBox, 2009: Absorbed Solar Radiation. [Web site]. Retrieved from https://www.engineeringtoolbox.com/solar-radiation-absorbedmaterials-d_1568.html.

Enríquez, R., Jiménez, M.J., Heras, M.R., 2017: Towards nonintrusive thermal load Monitoring of buildings: BES calibration. Applied Energy. $191 . \quad 44-54$. doi.org/10.1016/j.apenergy.2017.01.050.

Katili, A., Boukhanouf, R., Wilson, R., 2015: Space Cooling in Buildings in Hot and Humid Climates - a Review of the Effect of Humidity on the Applicability of Existing Cooling Techniques. SET 2015. doi.org/10.13140/RG.2.1.3011.5287.

Lebrun, J., 2021: Building thermal loads calculations.

Martin, R., 2019: R-Value Table, Insulation Values for Selected Materials. [Web site]. Retrieved from https://coloradoenergy.org/procorner/stuff/r-values.htm.

Nowak, H., 1991: The longwave radiative heat transfer of the building envelopes. Infrared Physics. 32. 357-363. doi.org/10.1016/0020-0891(91)90124-X.

Phil., 1977: Adopting A National Building Code of The Philippines (NBCP) Thereby Revising R.A. No. 6541. PD No. 1096. s.704.

Solar Irradiance Calculator. Solar Electricity Handbook. http://www.solarelectricityhandbook.com/solar-irradiance.html United Nations. (2014). World Urbanization Prospects: The 2014 Revision, Highlights (ST/ESA/SER.A/352).

Wu X., 2002: Geographic Information System theory and method. Electronics Industry Press, Beijing. 96 101

Zhao, D., Wang, S., Han, H., Wang, Y., Lin, D., 2018: Cooling Load Forecasting for Typical Office Buildings. 2018 IOP Conf. Ser.: Earth Environ. Sci. 208 012083. doi.org/10.1088/1755$1315 / 208 / 1 / 012083$ 